\title{
Study of the Quality Parameters and the Antioxidant Capacity for the FTIR-Chemometric Differentiation of Pistacia Vera Oils
}

\author{
Lydia Valasi ${ }^{1}$, Dimitra Arvanitaki ${ }^{1}$, Angeliki Mitropoulou ${ }^{1}$, Maria Georgiadou ${ }^{2}$ and \\ Christos S. Pappas ${ }^{1, *}$ \\ 1 Laboratory of Chemistry, Department of Food Science \& Human Nutrition, Agricultural University of \\ Athens, Iera Odos 75, 11855 Athens, Greece; lydia.valasi@aua.gr (L.V.); dimitrarvntk@gmail.com (D.A.); \\ aggelikimitropoulou8@gmail.com (A.M.) \\ 2 Laboratory of Food Process Engineering, Department of Food Science \& Human Nutrition, Agricultural \\ University of Athens, Iera Odos 75, 11855 Athens, Greece; m.georgiadou@aua.gr \\ * Correspondence: chrispap@aua.gr; Tel.: +30-2105294262
}

Academic Editors: Severina Pacifico and Simona Piccolella

Received: 29 February 2020; Accepted: 30 March 2020; Published: 1 April 2020

\begin{abstract}
The aim of this work was to characterize the pistachio oil of the Greek variety, "Aegina", evaluate its various quality indices, and investigate the potential use of FTIR as a tool to discriminate different oil qualities. For this purpose, the antioxidant capacity, the tocopherol content and the oxidation and degradation of fatty acids, as described by $\mathrm{k}, \Delta \mathrm{k}$, R-values, and free acidity were evaluated using 45 samples from eight different areas of production and two subsequent years of harvesting. The antioxidant capacity was estimated using 2,2'-azinobis(3-ethylbenzothiazoline-6-sulfonic acid diammonium salt (ABTS) and 2,2-diphenyl-1(2,4,6-trinitrophenyl)hydrazine (DPPH) assays, and the tocopherol content was quantified through HPLC analysis. FTIR spectra were recorded for all samples and multivariate analysis was applied. The results showed significant differences between the oil samples of different harvesting years, which were successfully discriminated by a representative FTIR spectral region based on R-value, total antioxidant capacity, and scavenging capacity, through ABTS. A similar approach could not be confirmed for the other quality parameters, such as the free acidity and the tocopherol content. This research highlighted the possibility of developing a simple, rapid, economic, and environment friendly method for the discrimination of pistachio oils according to their quality profile, through FTIR spectroscopy and multivariate analysis.
\end{abstract}

Keywords: Pistacia vera; antioxidant; quality; tocopherol; FTIR; discriminant analysis

\section{Introduction}

Pistacia, a genus of the Anacardiaceae family, includes at least eleven species, among them Pistacia vera $\mathrm{L}$. is the only edible commercial species [1]. The pistachio nut is an important agricultural commodity for a number of countries. Iran, United States, Turkey, Syria, Greece, Italy, and Spain are the main pistachio producers [2]. Pistachio nut can be considered to be a functional food, and has recently been ranked among the first 50 food products with the highest antioxidant potential [3]. The Dietary Guidelines recommend that consuming nuts (almonds, hazelnuts, walnuts, pistachios, pecans, and peanuts) as a part of a daily diet has a beneficial effect on human health [4].

The increasing consumption and demand for novel edible oils has led to a market expansion for the plant-derived oils, which receive particular attention due to their attractive sensory characteristics and their high nutritional properties [5]. The pistachio (Pistacia vera L.) oil content ranges from $50 \%$ to 
$60 \%$ (dry weight) in kernels, depending mainly on the cultivar, crop year, and geographic location. Even though no specific standards for pistachio oil have been set by the Codex Alimentarius on Fats and Oils, it is claimed to be a niche product [6,7]. It has gained attention due to its special organoleptic characteristics [8] and its richness in some nutrients and health promoting compounds that exhibit high antioxidant capacity $[9,10]$.

The most abundant components in pistachio oil are the fatty acids profiled as (mono- and poly-unsaturated, saturated, and as esters of triglycerides) [5]. The structure of fatty acids might change due to oxidation caused by bad agricultural practices, inappropriate harvesting time, and storage conditions, which can be detected by ultraviolet-visible (UV-Vis) spectroscopic measurements. Absorbencies at 232, 268, 270, and $274 \mathrm{~nm}$ are correlated with the state of oxidation, through the detection of secondary oxidation compounds, and possible adulteration with refined oils. Delta $(\Delta)$ $\mathrm{k}$ and R-value, resulting from the $\mathrm{k}_{232}, \mathrm{k}_{268}, \mathrm{k}_{270}$, and $\mathrm{k}_{274}$ values, are quick indicators of quality assessment of pistachio oil discriminating between high and poor quality oil and are correlated with possible adulteration [11]. Furthermore, the hydrolysis of the oil results in the formation of free fatty acid (FFA) and glycerol residues, indicating that higher quality oils exhibit very low FFA percentage and acidity [12]. As a result, free acidity is claimed to be an early indicator of the potential storage stability of the product. Additionally, it should be mentioned that the formation of oxidized compounds in pistachio oil is blocked by its own natural preservatives that carry out an important antioxidant activity. Pistachio oil contains numerous phenolic compounds that increase its shelf life, and prevent or reduce the damage to cells, caused by free radicals. The evaluation of the total antioxidant capacity is certainly a very useful property of the pistachio oil, ensuring the preservation of the most important health benefits and sensory characteristics. Additionally, tocopherols' content is associated with health benefits, as confirmed by clinical evidence [13]. Tocopherols are the main antioxidant components that are equally active to vitamin E, thus, are considered to be important biofunctional compounds of the human diet. Due to their non-polar nature, their presence in oils is profound [7]. The major tocopherol isomer in pistachio oil is $\gamma$-tocopherol, the most prevalent form of vitamin E [14].

Published works have shown that Fourier transform infrared (FTIR) spectroscopy combined with statistical methods for the discrimination of wines, according to the variety and vintage year, can be used as a rapid, accurate, simple, environment friendly, and economical approach $[15,16]$. The chemical composition of pistachio oil might be influenced by several factors like variety, climatic and agronomic conditions (weather, soil), the growing season, and agricultural practices $[17,18]$. Very limited data are available in the literature for the quality profile of the pistachio oil that is extracted from the main Greek pistachio variety, "Aegina".

The present work focused on the characterization of the pistachio oil of the variety "Aegina", evaluated various quality indices, and investigated the potential use of FTIR as a tool to discriminate different oil qualities.

\section{Results and Discussion}

All pistachio oil samples were stored in a freezer $\left(-20^{\circ} \mathrm{C}\right)$, in order to maintain their initial quality until analysis. Storage at low temperatures prevents from increasing or reducing the concentrations of oil components and helps to maintain the oil's primary quality [19].

\subsection{Oil Extraction}

The oil yield ranged between $59.7 \%-68.2 \% w / w$, with an average of $62.5 \pm 2.6 \% w / w$ for the samples of 2017 and between $52.5 \%-64.8 \% w / w$ for the samples of 2018, with a mean value of $59.6 \pm 2.8 \% w / w$, respectively. No statistically significant differences were observed in the oil yield between the samples obtained in the two years. 


\subsection{Evaluation of Antioxidant Capacity}

Total antioxidant capacity (TAC) and scavenging capacity of the analyzed pistachio oil samples, as measured by the DPPH and ABTS assays are shown in Table 1.

Table 1. Total antioxidant capacity (mM Trolox equivalents per $\mathrm{mL}$ pistachio oil) (TAC) and scavenging capacity (\%) of pistachio oils of different regions, as determined through the 2,2-diphenyl1-(2,4,6-trinitrophenyl)hydrazine (DPPH) and 2,2'-azinobis(3-ethylbenzothiazoline-6-sulfonic acid diammonium salt (ABTS) assays.

\begin{tabular}{|c|c|c|c|c|c|c|}
\hline \multirow{2}{*}{$\begin{array}{c}\text { Samples } \\
\text { No }\end{array}$} & \multirow{2}{*}{ Origin } & \multirow{2}{*}{$\begin{array}{c}\text { Year of } \\
\text { Harvest }\end{array}$} & \multicolumn{2}{|c|}{ TAC } & \multicolumn{2}{|c|}{ Scavenging Capacity } \\
\hline & & & DPPH & ABTS & DPPH & ABTS \\
\hline 1 & AEGINA & 2017 & 6.05 & 7.10 & 37.69 & 68.14 \\
\hline 2 & AEGINA & 2017 & 6.45 & 8.63 & 41.76 & 82.85 \\
\hline 3 & AEGINA & 2017 & 6.35 & 8.60 & 44.29 & 84.95 \\
\hline 4 & AEGINA & 2017 & 3.11 & 9.45 & 32.17 & 91.79 \\
\hline 5 & AEGINA & 2017 & 3.17 & 4.92 & 32.44 & 45.28 \\
\hline 6 & AEGINA & 2017 & 5.62 & 7.44 & 41.44 & 74.74 \\
\hline 7 & AEGINA & 2017 & 3.82 & 5.46 & 34.94 & 48.50 \\
\hline 8 & MEGARA & 2017 & 5.95 & 9.32 & 39.68 & 90.03 \\
\hline 9 & MEGARA & 2017 & 5.36 & 9.01 & 37.82 & 85.15 \\
\hline 10 & MEGARA & 2017 & 3.21 & 9.44 & 28.75 & 90.84 \\
\hline 11 & MEGARA & 2017 & 6.70 & 5.02 & 39.02 & 42.53 \\
\hline 12 & PHTHIOTIS & 2017 & 3.59 & 10.02 & 31.51 & 97.25 \\
\hline 13 & PHTHIOTIS & 2017 & 6.45 & 9.02 & 39.42 & 88.70 \\
\hline 14 & PHTHIOTIS & 2017 & 4.96 & 7.85 & 37.07 & 73.33 \\
\hline 15 & TRIZINA & 2017 & 4.68 & 8.73 & 35.33 & 81.85 \\
\hline 16 & AEGINA & 2018 & 2.12 & 9.63 & 39.30 & 82.26 \\
\hline 17 & AEGINA & 2018 & 7.92 & 8.23 & 37.97 & 76.33 \\
\hline 18 & AEGINA & 2018 & 7.10 & 8.91 & 42.70 & 83.65 \\
\hline 19 & AEGINA & 2018 & 6.49 & 8.58 & 40.40 & 84.02 \\
\hline 20 & AEGINA & 2018 & 1.99 & 7.99 & 40.52 & 74.89 \\
\hline 21 & AEGINA & 2018 & 8.44 & 8.61 & 47.87 & 82.05 \\
\hline 22 & AEGINA & 2018 & 4.83 & 8.38 & 34.05 & 77.05 \\
\hline 23 & AEGINA & 2018 & 5.86 & 9.46 & 40.19 & 90.34 \\
\hline 24 & AEGINA & 2018 & 5.30 & 7.71 & 34.84 & 66.41 \\
\hline 25 & AEGINA & 2018 & 7.47 & 8.27 & 38.43 & 75.91 \\
\hline 26 & AEGINA & 2018 & 6.70 & 8.72 & 41.40 & 86.10 \\
\hline 27 & AEGINA & 2018 & 5.69 & 7.96 & 36.21 & 73.62 \\
\hline 28 & EVIA & 2018 & 5.51 & 7.07 & 36.83 & 64.38 \\
\hline 29 & EVIA & 2018 & 3.80 & 9.49 & 28.96 & 91.06 \\
\hline 30 & EVIA & 2018 & 6.67 & 9.22 & 40.32 & 88.08 \\
\hline 31 & MEGARA & 2018 & 0.28 & 9.61 & 32.01 & 91.97 \\
\hline 32 & MEGARA & 2018 & 6.47 & 8.58 & 24.12 & 81.59 \\
\hline 33 & MEGARA & 2018 & 7.35 & 8.98 & 38.53 & 85.76 \\
\hline 34 & MEGARA & 2018 & 5.34 & 8.76 & 35.45 & 80.68 \\
\hline 35 & MEGARA & 2018 & 7.45 & 9.63 & 43.20 & 94.15 \\
\hline 36 & TRIZINA & 2018 & 7.65 & 8.47 & 44.10 & 77.16 \\
\hline 37 & PHTHIOTIS & 2018 & 5.84 & 9.80 & 38.83 & 93.99 \\
\hline 38 & PHTHIOTIS & 2018 & 6.04 & 6.78 & 40.30 & 61.75 \\
\hline 39 & PHTHIOTIS & 2018 & 0.10 & 9.22 & 31.87 & 87.01 \\
\hline 40 & PHTHIOTIS & 2018 & 1.35 & 9.83 & 36.60 & 94.10 \\
\hline 41 & PHTHIOTIS & 2018 & 1.40 & 8.28 & 36.50 & 74.18 \\
\hline 42 & PHTHIOTIS & 2018 & 5.82 & 10.00 & 36.09 & 96.60 \\
\hline 43 & VOLOS & 2018 & 10.28 & 9.95 & 52.29 & 96.31 \\
\hline 44 & THIVA & 2018 & 7.34 & 9.87 & 43.04 & 95.39 \\
\hline 45 & AVLONAS & 2018 & 8.43 & 9.16 & 45.60 & 88.19 \\
\hline
\end{tabular}


The Trolox calibration curve equations used for transforming absorbance inhibition values (AI) to Trolox equivalents (TE, mM) for the DPPH and ABTS assays, were Equations (1) and (2), respectively.

$$
\begin{aligned}
& \mathrm{AI}_{\mathrm{DPPH}}=(-0.388) \times \mathrm{TE}+0.797, \mathrm{R}^{2}=0.971 \\
& \mathrm{AI}_{\mathrm{ABTS}}=(-0.675) \times \mathrm{TE}+0.695, \mathrm{R}^{2}=0.995
\end{aligned}
$$

Antioxidant capacity, as determined by the DPPH assay, ranged between 3.11-6.70 mM with a mean TAC value of $5.03 \pm 1.3 \mathrm{mM}$, and between $0.10-10$ with a mean TAC value of $5.57 \pm 2.56 \mathrm{mM}$, for the samples of 2017 and 2018, respectively. Following this, the scavenging capacity ranged between $28.75 \%-44.29 \%$ and $28.96 \%-52.29 \%$ for the samples of 2017 and 2018 , with mean values of $36.89 \pm$ $4.33 \%$ and $38.62 \pm 5.55 \%$, respectively.

TAC values, as determined by the ABTS assay, ranged between $4.92-10.02 \mathrm{mM}$ and $7.07-10.00 \mathrm{mM}$ for the samples of 2017 and 2018, respectively, resulting in mean TAC values of $8.00 \pm 1.68 \mathrm{mM}$ and 8.84 $\pm 0.84 \mathrm{mM}$. The scavenging capacity, as measured by the ABTS assay, ranged between $42.53 \%-97.25 \%$, with an average of $76.39 \pm 17.75 \%$ for the 2017 samples and between $61.75 \%-96.6 \%$ for the 2018 samples, with a mean value of $83.17 \pm 9.56 \%$.

Concerning mean TAC and mean scavenging capacity values, results from the ABTS assay were significantly and consistently higher than those from DPPH in both years of harvest. This was due to the applicability of DPPH to hydrophobic systems. Specifically, DPPH was discolored in the presence of compounds that were capable of either transferring an electron or donating hydrogen (lipophilic components). On the other hand, ABTS was freely soluble in both organic and aqueous solvents, thus, it could be used to screen both hydrophilic and lipophilic antioxidants, exhibiting a better estimation of the overall antioxidant capacity of the foods [20,21]. Consequently, the results that were obtained from the ABTS assay were only considered for further statistical analysis. TAC and scavenging capacity, as estimated by ABTS were statistically different between 2017 and 2018. The differences were statistically significant.

\subsection{UV-Vis Spectroscopic Assessment}

The quality indices associated with the $\mathrm{k}_{232}, \mathrm{k}_{268}, \mathrm{k}_{270}, \mathrm{k}_{274}, \Delta \mathrm{k}$, and $\mathrm{R}$ values were evaluated in 45 pistachio oil samples and the results are displayed in Table 2. The European Quality Standard of Commission Regulation (EEC) No 2568/91 (Annex IX of the Regulation) has set the standard values for extra virgin olive oil (EVOO), as described in Table 2. Considering that an official protocol to predict the quality indicators of the pistachio oil or other nut oils based on the $\Delta \mathrm{k}$ and $\mathrm{R}$-value has not been established, the existing limits were used for the evaluation of pistachio oil samples.

The quality of the oil was assessed by the UV-Vis absorption screening, which identifies changes in the structure of fatty acids due to oxidation. A low absorption in this region is indicative of high-quality oil, whereas old, refined, and generally poor-quality oils show a greater level of absorption in this region, implying high degree of oxidation. The absorbance at $232 \mathrm{~nm}$ is caused by hydroperoxides (primary stage of oxidation) and conjugated dienes (intermediate stage of oxidation). The absorbance at $270 \mathrm{~nm}$ was caused by carbonylic compounds (secondary stage of oxidation) and conjugated trienes (technological treatments). In the oils, due to oxygen fixation in linolenic and linoleic acids' double bond position, hydroperoxides arise. The double bond provokes the formation of conjugate diene systems between the carbon atoms. This kind of conjugate systems presents a maximum absorption at $232 \mathrm{~nm}$. During more advanced oxidation states, the products are generated with conjugate diene systems of carbon-oxygen. The maximum absorption in this case ranges between 260-280 nm [11]. 
Table 2. Ultraviolet-visible (UV-Vis) spectroscopy, acid values (AV), and free fatty acid (FFA) of pistachio oil samples against the extra virgin olive oil (EVOO) corresponding values.

\begin{tabular}{|c|c|c|c|c|c|c|c|c|}
\hline $\begin{array}{c}\text { Samples } \\
\text { No }\end{array}$ & $k_{232}$ & $k_{268}$ & $k_{270}$ & $\mathbf{k}_{274}$ & $\Delta \mathbf{k}$ & $\mathbf{R}$ & $\begin{array}{c}\mathrm{AV}^{1} \\
\text { (as oleic acid) }\end{array}$ & $\%$ FFA $^{1}$ \\
\hline EVOO & $\leq 2.50$ & $\leq 0.22$ & $\leq 0.22$ & $\leq 0.22$ & $\leq 0.01$ & $\leq 11.36$ & $\leq 4.000$ & $\leq 0.350$ \\
\hline 1 & 0.126 & 0.009 & 0.009 & 0.010 & 0.000 & 14.073 & $6.615 \pm 0.000$ & $3.327 \pm 0.000$ \\
\hline 2 & 0.129 & 0.015 & 0.015 & 0.015 & 0.000 & 8.547 & $3.186 \pm 0.325$ & $1.603 \pm 0.163$ \\
\hline 3 & 0.146 & 0.010 & 0.011 & 0.011 & 0.000 & 13.759 & $2.249 \pm 0.000$ & $1.131 \pm 0.000$ \\
\hline 4 & 0.148 & 0.011 & 0.011 & 0.011 & 0.000 & 13.550 & $1.676 \pm 0.019$ & $0.843 \pm 0.010$ \\
\hline 5 & 0.145 & 0.017 & 0.018 & 0.018 & 0.000 & 8.155 & $1.676 \pm 0.019$ & $0.843 \pm 0.010$ \\
\hline 6 & 0.172 & 0.020 & 0.020 & 0.021 & 0.000 & 8.430 & $1.676 \pm 0.019$ & $0.843 \pm 0.010$ \\
\hline 7 & 0.164 & 0.010 & 0.011 & 0.011 & 0.000 & 15.537 & $3.373 \pm 0.000$ & $1.697 \pm 0.000$ \\
\hline 8 & 0.156 & 0.013 & 0.013 & 0.014 & 0.000 & 11.672 & $1.687 \pm 0.000$ & $0.848 \pm 0.000$ \\
\hline 9 & 0.166 & 0.020 & 0.020 & 0.021 & 0.000 & 8.308 & $0.532 \pm 0.001$ & $0.268 \pm 0.000$ \\
\hline 10 & 0.132 & 0.014 & 0.014 & 0.015 & 0.000 & 9.277 & $1.102 \pm 0.000$ & $0.555 \pm 0.000$ \\
\hline 11 & 0.173 & 0.027 & 0.027 & 0.027 & 0.000 & 12.281 & $2.509 \pm 0.336$ & $1.262 \pm 0.169$ \\
\hline 12 & 0.159 & 0.018 & 0.019 & 0.019 & 0.000 & 8.550 & $1.687 \pm 0.000$ & $0.848 \pm 0.000$ \\
\hline 13 & 0.142 & 0.009 & 0.009 & 0.009 & 0.000 & 15.987 & $1.124 \pm 0.000$ & $0.566 \pm 0.000$ \\
\hline 14 & 0.157 & 0.013 & 0.013 & 0.013 & 0.000 & 11.996 & $1.102 \pm 0.000$ & $0.555 \pm 0.000$ \\
\hline 15 & 0.173 & 0.025 & 0.025 & 0.025 & 0.000 & 6.854 & $1.676 \pm 0.019$ & $0.843 \pm 0.010$ \\
\hline 16 & 0.070 & 0.011 & 0.011 & 0.012 & 0.000 & 6.190 & $0.821 \pm 0.007$ & $0.413 \pm 0.003$ \\
\hline 17 & 0.075 & 0.016 & 0.016 & 0.016 & 0.000 & 4.699 & $0.805 \pm 0.269$ & $0.405 \pm 0.135$ \\
\hline 18 & 0.069 & 0.011 & 0.011 & 0.011 & 0.000 & 6.248 & $1.171 \pm 0.166$ & $0.589 \pm 0.083$ \\
\hline 19 & 0.071 & 0.011 & 0.011 & 0.012 & 0.000 & 6.179 & $0.994 \pm 0.161$ & $0.500 \pm 0.081$ \\
\hline 20 & 0.052 & 0.007 & 0.008 & 0.008 & 0.000 & 6.806 & $0.982 \pm 0.164$ & $0.494 \pm 0.082$ \\
\hline 21 & 0.068 & 0.011 & 0.012 & 0.012 & 0.000 & 5.842 & $1.087 \pm 0.009$ & $0.547 \pm 0.004$ \\
\hline 22 & 0.056 & 0.012 & 0.012 & 0.013 & 0.000 & 4.524 & $1.362 \pm 0.270$ & $0.685 \pm 0.136$ \\
\hline 23 & 0.073 & 0.014 & 0.014 & 0.014 & 0.000 & 5.254 & $0.989 \pm 0.148$ & $0.498 \pm 0.074$ \\
\hline 24 & 0.059 & 0.020 & 0.020 & 0.020 & 0.000 & 2.879 & $8.116 \pm 0.191$ & $4.082 \pm 0.096$ \\
\hline 25 & 0.071 & 0.011 & 0.011 & 0.012 & 0.000 & 6.202 & $0.807 \pm 0.014$ & $0.406 \pm 0.007$ \\
\hline 26 & 0.053 & 0.008 & 0.008 & 0.008 & 0.000 & 6.933 & $1.279 \pm 0.163$ & $0.643 \pm 0.082$ \\
\hline 27 & 0.074 & 0.015 & 0.015 & 0.016 & 0.000 & 4.831 & $0.995 \pm 0.166$ & $0.500 \pm 0.083$ \\
\hline 28 & 0.068 & 0.012 & 0.012 & 0.012 & 0.000 & 5.647 & $1.079 \pm 0.015$ & $0.543 \pm 0.008$ \\
\hline 29 & 0.070 & 0.013 & 0.014 & 0.014 & 0.000 & 5.197 & $0.800 \pm 0.251$ & $0.402 \pm 0.126$ \\
\hline 30 & 0.075 & 0.019 & 0.019 & 0.018 & 0.000 & 4.067 & $0.709 \pm 0.614$ & $0.357 \pm 0.309$ \\
\hline 31 & 0.073 & 0.015 & 0.015 & 0.016 & 0.000 & 4.865 & $1.004 \pm 0.156$ & $0.505 \pm 0.078$ \\
\hline 32 & 0.070 & 0.011 & 0.011 & 0.011 & 0.000 & 6.431 & $1.078 \pm 0.023$ & $0.542 \pm 0.011$ \\
\hline 33 & 0.054 & 0.011 & 0.012 & 0.012 & 0.000 & 4.666 & $0.978 \pm 0.151$ & $0.492 \pm 0.076$ \\
\hline 34 & 0.069 & 0.014 & 0.014 & 0.014 & 0.000 & 4.871 & $0.819 \pm 0.277$ & $0.412 \pm 0.139$ \\
\hline 35 & 0.072 & 0.014 & 0.014 & 0.015 & 0.000 & 5.050 & $1.007 \pm 0.157$ & $0.506 \pm 0.079$ \\
\hline 36 & 0.072 & 0.017 & 0.017 & 0.018 & 0.000 & 4.228 & $0.982 \pm 0.161$ & $0.494 \pm 0.081$ \\
\hline 37 & 0.070 & 0.012 & 0.012 & 0.013 & 0.000 & 5.764 & $0.898 \pm 0.151$ & $0.452 \pm 0.076$ \\
\hline 38 & 0.054 & 0.009 & 0.009 & 0.009 & 0.000 & 6.118 & $1.004 \pm 0.157$ & $0.505 \pm 0.079$ \\
\hline 39 & 0.053 & 0.010 & 0.011 & 0.011 & 0.000 & 5.009 & $0.808 \pm 0.016$ & $0.406 \pm 0.008$ \\
\hline 40 & 0.072 & 0.013 & 0.014 & 0.014 & 0.000 & 5.316 & $0.632 \pm 0.155$ & $0.318 \pm 0.078$ \\
\hline 41 & 0.053 & 0.011 & 0.011 & 0.011 & 0.000 & 4.969 & $1.009 \pm 0.160$ & $0.507 \pm 0.080$ \\
\hline 42 & 0.068 & 0.012 & 0.012 & 0.012 & 0.000 & 5.690 & $0.913 \pm 0.164$ & $0.459 \pm 0.083$ \\
\hline 43 & 0.070 & 0.012 & 0.012 & 0.013 & 0.000 & 5.771 & $0.821 \pm 0.004$ & $0.413 \pm 0.002$ \\
\hline 44 & 0.070 & 0.010 & 0.010 & 0.011 & 0.000 & 6.848 & $0.821 \pm 0.007$ & $0.413 \pm 0.003$ \\
\hline 45 & 0.053 & 0.010 & 0.010 & 0.010 & 0.000 & 5.476 & $0.911 \pm 0.166$ & $0.458 \pm 0.083$ \\
\hline
\end{tabular}

The mean $\mathrm{k}$ values for each harvesting year were $0.15 \pm 0.02$ (2017), $0.07 \pm 0.01$ (2018), $0.01 \pm 0.01$ (2017), $0.01 \pm 0.00$ (2018), $0.02 \pm 0.01$ (2017), $0.01 \pm 0.00$ (2018), $0.02 \pm 0.01$ (2017), and $0.01 \pm 0.00$ (2018) for $\mathrm{k}_{232}, \mathrm{k}_{268}, \mathrm{k}_{270}$, and $\mathrm{k}_{274}$, respectively. $\Delta \mathrm{k}$ was $0.00 \pm 0.00$ for all samples, regardless of the year of harvest or the origin. The mean R-values were $11.13 \pm 3.00$ and $5.42 \pm 0.91$, for the samples of 2017 and 2018, respectively. 
There were no significant differences between the years of harvest, based on $\mathrm{k}$ and $\Delta \mathrm{k}$, as all measurements ranged into the high-quality limits. As for the R-value, the 2017 samples were systematically higher than 2018 samples. Specifically, 82\% of the samples, which mostly originated from 2018 harvest complied with the EVOO standard, except for the R-value of the remaining $18 \%$ of the total samples, which belonged to the 2017 harvest (samples 1, 3, 4, 7, 8, 11, 13, and 14).

\subsection{Acid $(A V)$ and FFA Values}

$\mathrm{AV}$ value is a measure of the number of carboxylic acid groups. It is used as an indicator for edibility of oil and is expressed in milligrams per gram. However, FFA are expressed as a percentage of oleic acid. According to the Codex Standard for Edible Fats and Oils, acid value of oil suitable for edible purposes should not exceed $4 \mathrm{mg} / \mathrm{g}$.

FFA has been reported to play a very important role in the aroma and flavor. FFA also contributes to the organoleptic quality of foods, when present in adequate concentration. FFA content is an index of lipase activity and an indicator of freshness, storage time, and stability of many fat-rich foods. It is well-known that FFAs are more susceptible to lipid oxidation, leading to rancidity and production of off-odor, compared to intact fatty acids in triglycerides. It is considered to be an early indicator of the storage stability of the oil [22], with a supreme limit that is less than $0.35 \%$ [11].

As presented in Table 2, the AV ranged from 0.53 to 6.61 and from 0.63 to $8.12 \mathrm{mg} / \mathrm{g}$ for 2017 and 2018 , respectively. The mean AV $(1.19 \pm 1.32 \mathrm{mg} / \mathrm{g}$ oil $)$ of 2018 exhibited lower values than the mean AV $(2.12 \pm 1.46 \mathrm{mg} / \mathrm{g}$ oil) of 2017 . The FFA content ranged from $0.27 \%$ to $3.33 \%$ and from $0.32 \%$ to $4.08 \%$ for 2017 and 2018, respectively. Similarly, the mean FFA $(0.60 \pm 0.66 \%)$ of 2018 was lower than the mean FFA $(1.07 \pm 0.73)$ of 2017 , leading to the conclusion that the 2018 harvesting exhibited a superior antioxidant capacity. Based on the standard for edible oils, only two samples (No. 1 and No. 24) from the area of Aegina showed values out of the acceptable levels of AV, whereas only two samples (No. 9 and No. 40) exhibited acceptable levels of FFA content.

\subsection{Tocopherol Analysis}

The limit of detection (LOD) for tocopherol analysis was $0.15 \mu \mathrm{g} / \mathrm{mL}$. The tocopherol calibration curves used for the qualitative separation of samples were (Equations (3)-(6)):

$$
\begin{aligned}
& \text { Area }(\mathrm{mV} \times \mathrm{s})=8.0556 \times \mathrm{C}_{\alpha-\mathrm{T}}(\mu \mathrm{g} / \mathrm{mL})+0.531, \mathrm{R}^{2}=0.999 \\
& \text { Area }(\mathrm{mV} \times \mathrm{s})=10.724 \times \mathrm{C}_{\beta-\mathrm{T}}(\mu \mathrm{g} / \mathrm{mL})+1.9311, \mathrm{R}^{2}=0.998 \\
& \text { Area }(\mathrm{mV} \times \mathrm{s})=13.786 \times \mathrm{C}_{\gamma-\mathrm{T}}(\mu \mathrm{g} / \mathrm{mL})+2.5428, \mathrm{R}^{2}=0.978 \\
& \text { Area }(\mathrm{mV} \times \mathrm{s})=14.617 \times \mathrm{C}_{\delta-\mathrm{T}}(\mu \mathrm{g} / \mathrm{mL})+2.1461, \mathrm{R}^{2}=0.997
\end{aligned}
$$

As for recovery evaluation, the amount of vitamin $\mathrm{E}$ isomers added to the samples corresponded to $98.47 \%, 77.86 \%, 47.44 \%$, and $110.37 \%$ (Equation (14)) of the expected $\alpha-\mathrm{T}, \beta-\mathrm{T}, \gamma-\mathrm{T}$, and $\delta$-T, and the intraday analytical precision was 3.08\%, 5.99\%, 4.89\%, and 2.75\% (Equation (15)), respectively.

Figure 1 illustrates the separation of the most important vitamin E isomers, as determined with the HPLC method, using fluorescence detection. The retention times for the $\alpha-, \beta-, \gamma-$, and $\delta$-tocopherols were $8,10,12$, and $16 \mathrm{~min}$, approximately. The concentration of each tocopherol for all 45 pistachio oil samples is presented in Table 3. The results were obtained and corrected on the basis of recovery and repeatability of the method, as determined by the coefficient of variation $(\mathrm{CV})$. The tocopherol contents of pistachio oils expressed as $10^{2} \mu \mathrm{g} / \mathrm{mL}$ pistachio oil, ranged from 0.53 (No. 25) to 5.90 (No. 43 ), 0.33 (No. 13) to 2.25 (No. 29), 97.56 (No. 36) to 235.06 (No. 6), and 0.84 (No. 12) to 2.31 (No. 20) for $\alpha-$, $\beta-, \gamma-$, and $\delta$-tocopherol, respectively. The above minimum and maximum values corresponded to 13.25-147.50, 8.25-56.25, 2439.00-5876.50, and 21.00-57.75 mg/kg of pistachio oil for $\alpha_{-}^{-}, \beta_{-}^{-}, \gamma_{-}^{-}$, and $\delta$-tocopherol, respectively. It is important to mention that $\gamma$-tocopherol is coeluted with $\beta$-tocotrienol, as a result, the calculated content of $\gamma$-tocopherol includes both isomers. The data indicate that the 
main form in all samples was $\gamma$-tocopherol (by coelution with $\beta$-tocotrienol), whereas the $\beta$-tocopherol content was limited. These results are in agreement with Martinez et al. (2016) [23]. The minimum and maximum values of each tocopherol presented in the samples were compared to the standard for vegetable oils provided by the Codex Alimentarius Commission on Fats and Oils (Table 4). With regards to pistachio oils, the quantity of $\alpha$ - and $\delta$-tocopherol, as measured in the present work for the variety "Aegina", ranges within the limits that have been set by the standard. However, no values were described for the $\beta$-tocopherol and $\beta$-tocotrienol, in contrast to the present study.
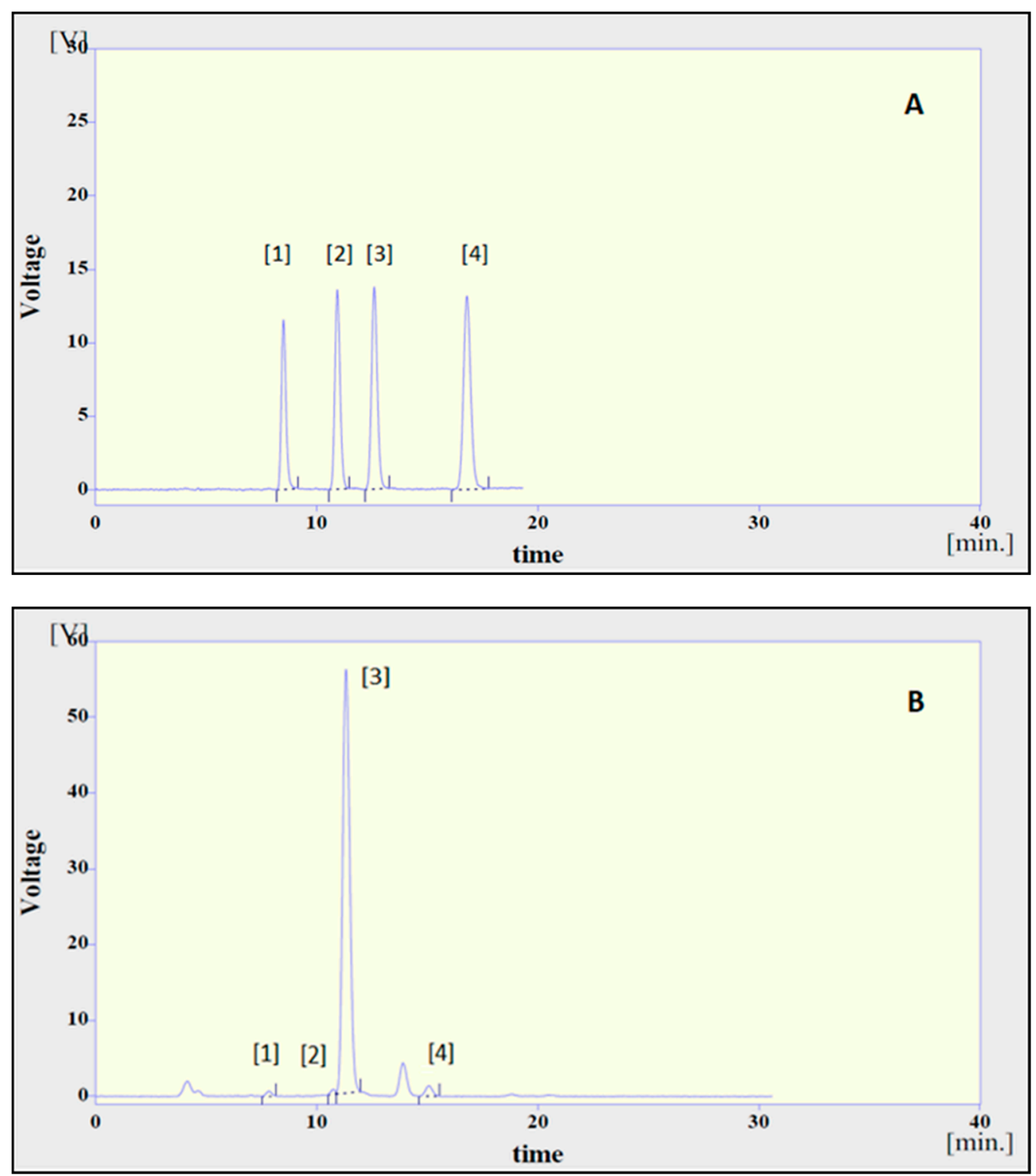

Figure 1. Chromatogram of a working standard mixture (A) and of a pistachio oil sample (B), determined through high performance liquid chromatography (HPLC)-fluorescence. Peaks: 1, $\alpha$-tocopherol; 2 , $\beta$-tocopherol; 3, $\gamma$-tocopherol, and $\beta$-tocotrienol; 4, $\delta$-tocopherol. 
Table 3. Tocopherol $(\mathrm{T})$ content $\left(\times 10^{2} \mu \mathrm{g} / \mathrm{mL}\right.$ pistachio oil) obtained by Soxhlet extraction and repeatability assessment.

\begin{tabular}{|c|c|c|c|c|c|c|c|c|}
\hline \multirow{2}{*}{ Samples No } & \multicolumn{4}{|c|}{ Concentration $^{1}$} & \multicolumn{4}{|c|}{ Repeatability $(\mathrm{CV} \%, n=3)$} \\
\hline & $\alpha-\mathrm{T}$ & $\beta-T$ & $\gamma-\mathrm{T}^{2}$ & $\delta-\mathrm{T}$ & $\alpha-T$ & $\beta-T$ & $\gamma-\mathrm{T}$ & $\delta-\mathrm{T}$ \\
\hline 1 & $1.57 \pm 0.16$ & $1.07 \pm 0.24$ & $186.77 \pm 3.65$ & $1.79 \pm 0.04$ & 10.52 & 22.26 & 1.95 & 2.13 \\
\hline 2 & $1.32 \pm 0.10$ & $1.14 \pm 0.19$ & $202.72 \pm 12.77$ & $1.73 \pm 0.13$ & 7.45 & 16.60 & 6.30 & 7.35 \\
\hline 3 & $0.99 \pm 0.05$ & $0.63 \pm 0.09$ & $191.13 \pm 4.38$ & $1.57 \pm 0.02$ & 4.94 & 13.88 & 2.29 & 1.62 \\
\hline 4 & $1.73 \pm 0.15$ & $0.39 \pm 0.05$ & $222.09 \pm 10.95$ & $1.59 \pm 0.05$ & 8.54 & 12.38 & 4.93 & 3.09 \\
\hline 5 & $1.86 \pm 0.30$ & $0.45 \pm 0.24$ & $187.09 \pm 3.09$ & $1.80 \pm 0.15$ & 16.21 & 52.60 & 1.65 & 8.10 \\
\hline 6 & $3.12 \pm 0.29$ & $1.13 \pm 0.46$ & $235.06 \pm 7.77$ & $2.11 \pm 0.07$ & 9.27 & 40.99 & 3.31 & 3.42 \\
\hline 7 & $2.13 \pm 0.12$ & $1.10 \pm 0.10$ & $210.49 \pm 18.33$ & $1.77 \pm 0.14$ & 5.86 & 8.88 & 8.71 & 7.83 \\
\hline 8 & $1.53 \pm 0.16$ & $1.06 \pm 0.04$ & $174.01 \pm 6.78$ & $1.37 \pm 0.09$ & 10.31 & 4.14 & 3.89 & 6.62 \\
\hline 9 & $0.59 \pm 0.17$ & $0.97 \pm 0.17$ & $173.56 \pm 11.78$ & $1.41 \pm 0.11$ & 29.47 & 17.01 & 6.79 & 8.17 \\
\hline 10 & $1.24 \pm 0.07$ & $0.38 \pm 0.03$ & $173.29 \pm 5.46$ & $1.06 \pm 0.09$ & 5.72 & 7.18 & 3.15 & 8.38 \\
\hline 11 & $1.71 \pm 0.27$ & $0.98 \pm 0.12$ & $170.07 \pm 12.59$ & 1.78 & 15.60 & 12.51 & 7.41 & 0.10 \\
\hline 12 & $1.32 \pm 0.18$ & $0.83 \pm 0.31$ & $134.59 \pm 4.15$ & $0.84 \pm 0.22$ & 13.46 & 37.48 & 3.08 & 26.52 \\
\hline 13 & $1.80 \pm 0.13$ & $0.33 \pm 0.20$ & $199.49 \pm 7.96$ & $1.60 \pm 0.06$ & 7.49 & 60.45 & 3.99 & 3.48 \\
\hline 14 & $3.37 \pm 0.44$ & $0.55 \pm 0.15$ & $231.93 \pm 9.84$ & $1.17 \pm 0.19$ & 12.96 & 26.87 & 4.24 & 16.08 \\
\hline 15 & $1.87 \pm 0.17$ & $0.48 \pm 0.07$ & $199.88 \pm 6.87$ & $1.58 \pm 0.12$ & 9.16 & 14.98 & 3.44 & 7.35 \\
\hline 16 & $2.29 \pm 0.06$ & $1.25 \pm 0.06$ & $193.13 \pm 5.12$ & $2.01 \pm 0.14$ & 2.75 & 4.69 & 2.65 & 7.11 \\
\hline 17 & $1.59 \pm 0.08$ & $0.86 \pm 0.11$ & $184.07 \pm 9.59$ & $1.81 \pm 0.01$ & 5.20 & 13.06 & 5.21 & 0.39 \\
\hline 18 & $4.10 \pm 0.08$ & $1.68 \pm 0.11$ & $223.82 \pm 2.45$ & $2.20 \pm 0.09$ & 2.04 & 6.45 & 1.09 & 4.24 \\
\hline 19 & $2.83 \pm 0.20$ & $1.26 \pm 0.11$ & $201.78 \pm 9.48$ & $1.89 \pm 0.22$ & 7.16 & 8.61 & 4.70 & 11.67 \\
\hline 20 & $2.78 \pm 0.35$ & $0.87 \pm 0.15$ & $204.80 \pm 2.12$ & $2.31 \pm 0.28$ & 12.65 & 17.70 & 1.04 & 12.12 \\
\hline 21 & $3.22 \pm 0.67$ & $0.77 \pm 0.07$ & $195.44 \pm 5.02$ & $1.97 \pm 0.04$ & 20.91 & 8.57 & 2.57 & 1.91 \\
\hline 22 & $1.72 \pm 0.14$ & $1.33 \pm 0.03$ & $152.10 \pm 2.14$ & $1.73 \pm 0.13$ & 8.33 & 2.01 & 1.41 & 7.36 \\
\hline 23 & $1.73 \pm 0.02$ & $0.65 \pm 0.12$ & $157.93 \pm 4.27$ & $1.79 \pm 0.03$ & 1.04 & 18.85 & 2.70 & 1.79 \\
\hline 24 & $2.15 \pm 0.20$ & $0.83 \pm 0.11$ & $213.88 \pm 3.55$ & $2.12 \pm 0.04$ & 9.29 & 13.35 & 1.66 & 1.99 \\
\hline 25 & $0.53 \pm 0.03$ & $1.01 \pm 0.28$ & $114.45 \pm 39.60$ & $1.43 \pm 0.43$ & 6.62 & 27.72 & 34.60 & 30.02 \\
\hline 26 & $2.56 \pm 0.17$ & $1.79 \pm 0.34$ & $196.23 \pm 2.86$ & $1.99 \pm 0.10$ & 6.73 & 19.18 & 1.46 & 5.07 \\
\hline 27 & $1.88 \pm 0.25$ & $0.96 \pm 0.08$ & $203.79 \pm 2.77$ & $2.13 \pm 0.08$ & 13.14 & 8.17 & 1.36 & 3.78 \\
\hline 28 & $4.39 \pm 0.15$ & $1.79 \pm 0.11$ & $216.32 \pm 7.47$ & $1.88 \pm 0.07$ & 3.35 & 6.38 & 3.45 & 3.52 \\
\hline 29 & $3.07 \pm 0.28$ & $2.25 \pm 0.14$ & $174.04 \pm 4.57$ & $1.79 \pm 0.11$ & 9.03 & 6.40 & 2.63 & 6.02 \\
\hline 30 & $3.51 \pm 0.22$ & $1.37 \pm 0.16$ & $178.60 \pm 6.09$ & $1.73 \pm 0.13$ & 6.36 & 11.48 & 3.41 & 7.28 \\
\hline 31 & $2.93 \pm 0.12$ & $0.66 \pm 0.07$ & $160.22 \pm 2.28$ & $1.41 \pm 0.17$ & 4.15 & 11.13 & 1.42 & 12.27 \\
\hline 32 & $1.98 \pm 0.20$ & $1.75 \pm 0.21$ & $191.41 \pm 7.90$ & $2.17 \pm 0.31$ & 10.17 & 12.13 & 4.13 & 14.22 \\
\hline 33 & $0.70 \pm 0.11$ & $1.11 \pm 0.08$ & $119.08 \pm 4.32$ & $1.29 \pm 0.03$ & 15.51 & 7.03 & 3.62 & 2.64 \\
\hline 34 & $2.26 \pm 0.41$ & $0.45 \pm 0.00$ & $156.43 \pm 1.80$ & $1.33 \pm 0.04$ & 18.36 & 0.56 & 1.15 & 3.26 \\
\hline 35 & $2.23 \pm 0.48$ & $1.58 \pm 0.16$ & $203.53 \pm 5.74$ & $1.96 \pm 0.24$ & 21.50 & 9.91 & 2.82 & 12.24 \\
\hline 36 & $1.56 \pm 0.22$ & $1.07 \pm 0.32$ & $97.56 \pm 8.15$ & $1.58 \pm 0.03$ & 14.41 & 30.46 & 8.36 & 2.11 \\
\hline 37 & $3.28 \pm 0.07$ & $0.62 \pm 0.02$ & $157.49 \pm 5.24$ & $1.20 \pm 0.12$ & 2.22 & 3.61 & 3.33 & 10.15 \\
\hline 38 & $4.15 \pm 0.04$ & $0.78 \pm 0.07$ & $185.36 \pm 11.25$ & $1.50 \pm 0.04$ & 1.03 & 9.21 & 6.07 & 2.41 \\
\hline 39 & $2.11 \pm 0.19$ & $1.82 \pm 0.21$ & $164.57 \pm 23.70$ & $1.96 \pm 0.74$ & 9.01 & 11.51 & 14.40 & 37.91 \\
\hline 40 & $1.47 \pm 0.13$ & $1.96 \pm 0.06$ & $169.36 \pm 7.54$ & $1.79 \pm 0.10$ & 8.67 & 3.24 & 4.45 & 5.86 \\
\hline 41 & $2.47 \pm 0.43$ & $0.71 \pm 0.09$ & $158.31 \pm 14.51$ & $1.46 \pm 0.32$ & 17.35 & 12.85 & 9.16 & 21.66 \\
\hline 42 & $4.20 \pm 0.07$ & $2.22 \pm 0.65$ & $170.70 \pm 2.42$ & $1.90 \pm 0.02$ & 1.68 & 29.47 & 1.42 & 1.20 \\
\hline 43 & $5.90 \pm 0.22$ & $1.56 \pm 0.37$ & $225.78 \pm 5.51$ & $1.99 \pm 0.05$ & 3.69 & 23.81 & 2.44 & 2.76 \\
\hline 44 & $1.98 \pm 0.19$ & $0.70 \pm 0.02$ & $157.50 \pm 4.63$ & $1.59 \pm 0.05$ & 9.69 & 2.29 & 2.94 & 2.99 \\
\hline 45 & $2.58 \pm 0.11$ & $\mathrm{ND}^{3}$ & $216.02 \pm 3.06$ & $1.98 \pm 1.12$ & 4.47 & - & 1.42 & 56.55 \\
\hline
\end{tabular}

\footnotetext{
${ }^{1}$ expressed as mean $\pm \mathrm{SD} ;{ }^{2} \gamma$-T is co-eluted with $\beta$-tocotrienol; ${ }^{3} \mathrm{ND}=$ Not Detected.
} 
Table 4. Limits (min-max) of tocopherol content ( $\mathrm{mg} / \mathrm{kg}$ dried sample) for different vegetable oils. according to the Codex Alimentarius Commission on Fats and Oils Standard.

\begin{tabular}{cccccc}
\hline Oils & $\alpha-\mathbf{T}$ & $\beta-\mathbf{T}$ & $\boldsymbol{\gamma}-\mathbf{T}$ & $\boldsymbol{\delta}-\mathbf{T}$ & Total \\
\hline almond & $20-545$ & $\mathrm{ND}^{1}-10$ & $5-104$ & ND-5 & $20-600$ \\
hazelnut & $100-420$ & $6-12$ & $18-194$ & ND-10 & $200-600$ \\
walnut & ND-170 & ND-110 & $120-400$ & ND-60 & $309-455$ \\
pistachio & $10-330$ & ND & $0-100$ & ND-50 & $100-600$ \\
flax/linseed & $2-20$ & ND & $100-712$ & $3-14$ & $150-905$ \\
avocado & $50-450$ & ND & $10-20$ & ND-10 & $50-450$ \\
\hline
\end{tabular}

${ }^{1} \mathrm{ND}=$ Not Detected.

The mean values of each harvesting year were $1.74 \pm 0.72$ (2017), $2.60 \pm 1.15$ (2018), $0.77 \pm 0.31$ (2017), $1.19 \pm 0.55$ (2018), $192.81 \pm 26.41$ (2017), $178.12 \pm 32.01$ (2018), $1.55 \pm 0.33$ (2017), and $1.80 \pm$ 0.29 (2018), expressed as $10^{2} \mu \mathrm{g} / \mathrm{mL}$ pistachio oil for $\alpha-, \beta-, \gamma-$, and $\delta$-tocopherol, respectively. The aforementioned values corresponded to a total tocopherol content of 196.87 for the 2017 harvest and 183.71 for 2018 (expressed as $10^{2} \mu \mathrm{g} / \mathrm{mL}$ pistachio oil).

\subsection{FTIR Spectroscopy Study}

Figure 2 shows two representative FTIR spectra of a pistachio oil sample with its basic peaks marked. The presented spectra depict samples of common origin but of different harvesting year. It is interesting to note that both spectra are optically very similar and, thus, the use of discriminant analysis is necessary. Each peak corresponds to a certain wavenumber that is attributed to specific vibrations and chemical structures of components from pistachio oil (Table 5).

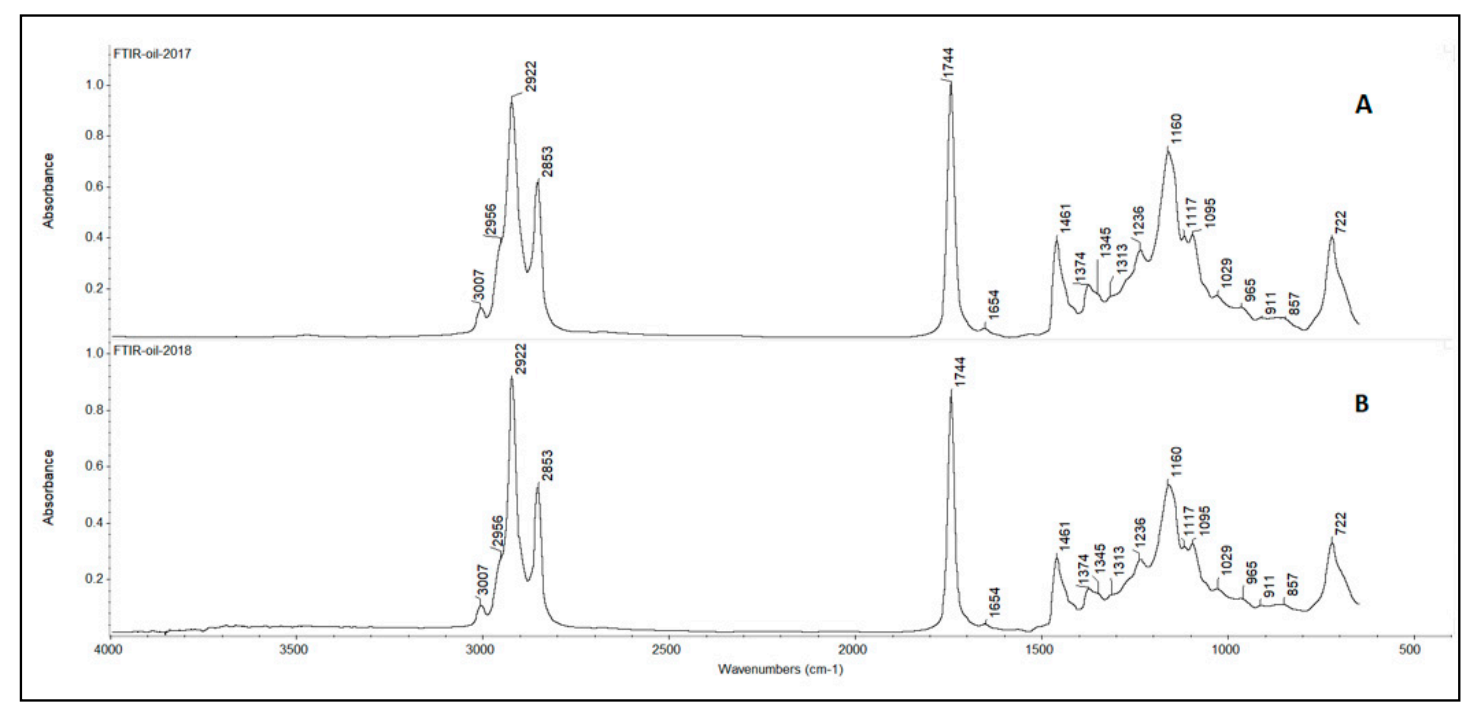

Figure 2. Representative FTIR spectra of pistachio oil samples from the same origin, but from different years of harvest, 2017 (A) and 2018 (B). 
Table 5. Peak correspondence of the pistachio oil FTIR spectra.

\begin{tabular}{|c|c|c|c|}
\hline Wavenumber $\left(\mathrm{cm}^{-1}\right)$ & Function Group & Abbreviations & Reference \\
\hline 3007 & $\mathrm{C}-\mathrm{H}$ symmetric stretching vibration of $-\mathrm{CH}_{3}$ & $\mathrm{v}_{\mathrm{s}}\left(\mathrm{CH}_{3}\right)$ & [24-26] \\
\hline 2956 & $\mathrm{C}-\mathrm{H}$ asymmetric stretching vibration of $-\mathrm{CH}_{3}$ & $\mathrm{~V}_{\text {as }}\left(\mathrm{CH}_{3}\right)$ & [27] \\
\hline 2922 & $\mathrm{C}-\mathrm{H}$ asymmetric stretching vibration of $-\mathrm{CH}_{2}-$ & $\mathrm{v}_{\text {as }}\left(\mathrm{CH}_{2}\right)$ & {$[24-26,28-30]$} \\
\hline 2853 & $\mathrm{C}-\mathrm{H}$ symmetric stretching vibration of $-\mathrm{CH}_{2}^{-}$ & $\mathrm{v}_{\mathrm{S}}\left(\mathrm{CH}_{2}\right)$ & {$[24,26-28,30]$} \\
\hline 1744 & $\mathrm{C}=\mathrm{O}$ stretching vibration & $\mathrm{v}(\mathrm{C}=\mathrm{O})$ & {$[24,25,28,29]$} \\
\hline 1654 & $>\mathrm{C}=\mathrm{C}<$ cis-olefinic stretching vibration & $\mathrm{v}(\mathrm{C}=\mathrm{C})$ & [24] \\
\hline 1461 & $\mathrm{C}-\mathrm{H}$ in-plane bending vibration of $-\mathrm{CH}_{2}-$ (scissoring) & $\delta_{\mathrm{S}}\left(\mathrm{CH}_{2}\right)$ & {$[24,26,30,31]$} \\
\hline 1374 & $\mathrm{C}-\mathrm{H}$ symmetric bending vibration of $-\mathrm{CH}_{3}$ & $\delta\left(\mathrm{CH}_{3}\right)$ & {$[25,27,28,30]$} \\
\hline 1345,1313 & $-\mathrm{CH}_{2}$ - out-of-plane bending vibration (wagging) & $\omega\left(\mathrm{CH}_{2}\right)$ & [27] \\
\hline $1236,1160,1117$ & C-O asymmetric stretching vibration & $v_{\text {as }}(\mathrm{C}-\mathrm{O})$ & {$[25,27,28,30,31]$} \\
\hline 1095,1029 & in-phase-C-C stretching vibration & $v(\mathrm{C}-\mathrm{C})$ & {$[27,30]$} \\
\hline 965 & $\mathrm{C}-\mathrm{H}$ in-plane bending vibration (scissoring) & $\delta_{\mathrm{s}}(\mathrm{C}=\mathrm{C}=\mathrm{C})$ & {$[27,28]$} \\
\hline 911,857 & $-\mathrm{CH}_{2}-$ plane vibration & $\gamma\left(\mathrm{CH}_{2}\right)$ & {$[27,28]$} \\
\hline 722 & $-\mathrm{CH}=\mathrm{CH}$ - cis-stretching vibration & $\mathrm{v}(\mathrm{C}=\mathrm{C})$ & {$[24,28,29]$} \\
\hline
\end{tabular}

Pistachios are rich in lipids (48\%-63\%), with a balanced content of mono- $(56 \%-77 \%)$ and poly-unsaturated $(10 \%-31 \%)$ fatty acids, protein $(18 \%-22 \%)$, and dietary fibers $(8 \%-12 \%)$. Moreover, they present a high content of bioactive compounds, such as tocopherols, phytosterols, and phenolic compounds [32]. Main lipid acids absorb in the same spectral region $\left(3007-772 \mathrm{~cm}^{-1}\right)$ as phenols, tocopherols, and sterols $[24,26,28,33,34]$.

\subsection{Statistical Analysis}

In case the number of samples for each test group exceeded 30, Levene's test (t-test) was applied without testing whether the data were normally distributed or not. Additionally, a normality test was applied in order to accept or reject the null hypothesis that each test group was statistically different from a normal distribution. Kolmogorov-Smirnov's and Shapiro-Wilk's normality tests evaluated if the groups followed normal distribution ( $p$-value $>0.05)$, with the Shapiro-Wilk's result exhibiting higher validity, as it comes from a more conservative test. If the data did not follow a normal distribution, the appropriate normalization was made to fix the skewness and kurtosis values, at the accepted levels.

When the normality test was confirmed, Levene's test was used to assess the equality of variances. Levene's test checked the null hypothesis that the test group variances were equal (homogeneity of variance or homoscedasticity). If the resulting $p$-value of Levene's test was less than the required significance level (typically 0.05), the obtained differences in sample variances were unlikely to have occurred, based on random sampling from a population with equal variances, so the test group were significantly different.

MetaboAnalyst checked data integrity and continued on to data filtering. The purpose of the data filtering was to identify and remove variables that were unlikely to be of use when modeling the data. This step is strongly recommended for datasets with a large number of variables, many of which are from baseline noises. Based on the total number of variables, $10 \%$ of data were filtered, logarithmically transformed, and auto-scaled (mean-centered and divided by the SD of each variable).

The total number of samples (45 pistachio oil samples) was differentiated according to their year of harvest.

\subsubsection{Discrimination Based on Antioxidant Capacity}

Levene's test of SPSS was used to assess the equality of ABTS variances for two years of harvest, 2017 and 2018. Levene's test tested the null hypothesis that the ABTS variances of 2017 and 2018 were equal. $P$-value less than 0.05 rejected the null hypothesis and proved that the TAC (Wilks' Lambda $=0.895$ ) and the scavenging capacity (Wilks' Lambda $=0.939)$ of ABTS were different in 2017 and 2018. From cross-validated grouped cases, $71.10 \%$ were classified correctly according to their antioxidant capacity and year of harvest. 


\subsubsection{Discrimination Based on R-Value Study}

Based on R-values, $86.70 \%$ of cross-validated grouped cases were correctly classified to their year of harvest and the $P$-value $(<0.001)$ proved the accuracy and robustness of the forecasting model, using SPSS. Therefore, the R-value of the samples was exploited to classify the samples according to the year of production (Wilks' Lambda $=0.315)$.

\subsubsection{Discrimination Based on Acid Value and Free Fatty Acid}

Levene's test examined the null hypothesis that the AV of 2017 and 2018 harvest were equal and the same assumption was made for the FFA content. The results ( $p$-value $>0.05)$ failed to reject the null hypothesis and indicated that AV and FFA were not significantly different between the two years of harvest. Discrimination analysis displayed a percentage of correct classification at $71.10 \%$ (cross-validated grouped cases).

\subsubsection{Discrimination Based on the Tocopherol Analysis}

SPSS could not discriminate between the years of harvest of the 45 pistachio oil samples, according to their total tocopherol content. Levene's test for equality of variances between the 2017 and 2018 harvest exhibited a $p$-value $>0.05$ and a $61.40 \%$ cross-validation level.

\subsubsection{Discrimination Based on FTIR Spectroscopy Study}

The spectral regions 3030-2795 and 1805-650 $\mathrm{cm}^{-1}$ were selected for the discriminant analysis, i.e., the regions where the peaks were observed (Figure 2). Applying the principal component analysis, the initial set of variables was reduced to a number of hidden variables of principal components (PC). The scree plot (Figure 3) revealed that the greatest impact on the variance of the analysed spectra for the pistachio oil samples was related to the first two principal components. Figures 4 and 5 present the score and loading plot for the principal components (PC) in the principal components analysis (PCA) model. The pistachio oil samples were clearly classified into two groups (2017 and 2018 harvest year). As depicted in Figure 6, MetaboAnalyst could correctly classify 100\% of the cross-validated grouped cases, according to their chemical composition and year of harvest with $\mathrm{R}^{2}=0.992$ and $\mathrm{Q}^{2}=0.987$, which indicate a high predictive accuracy. $P$-values less than 0.05 proved that the FTIR method could be used as an accurate rapid screening tool for the differentiation of pistachio oils by their year of harvest.

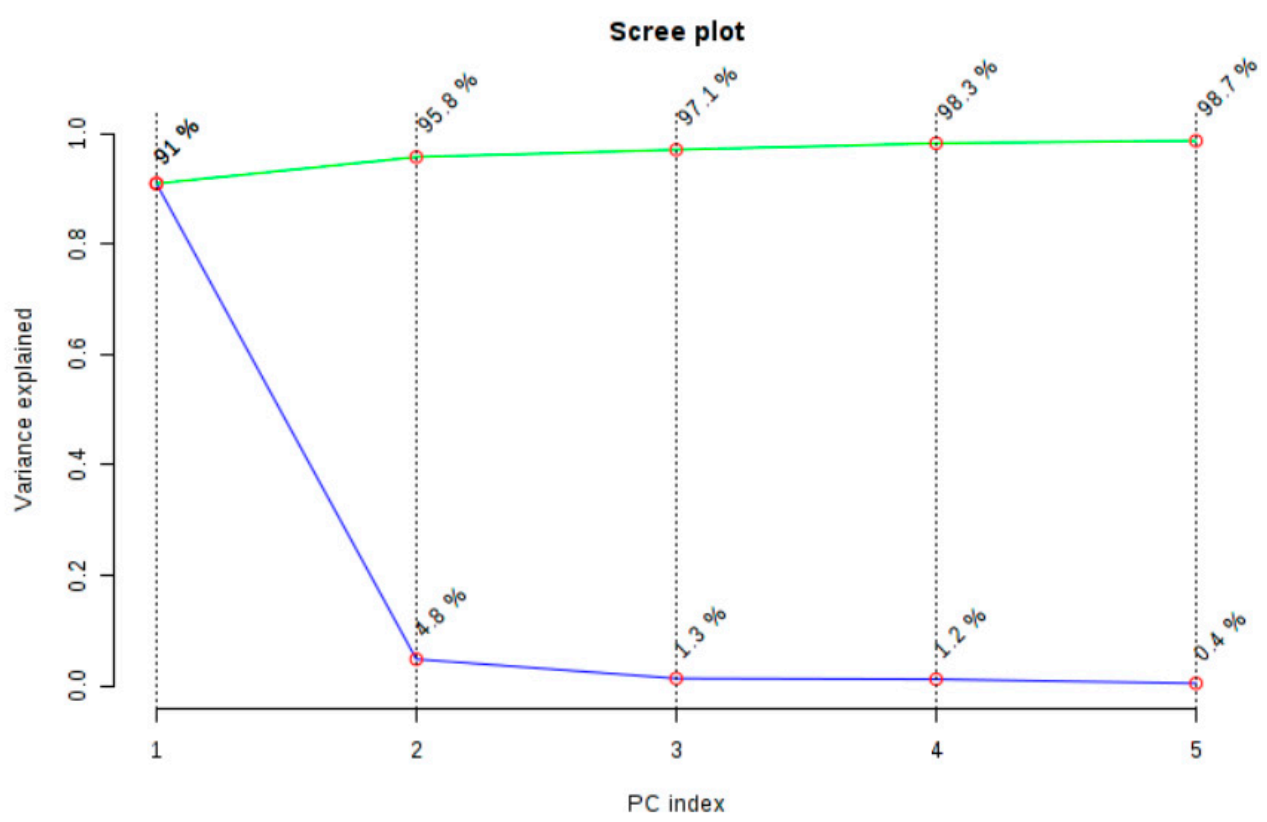

Figure 3. Plot of explained variance for principal components analysis (PCA) of the FTIR spectra. 


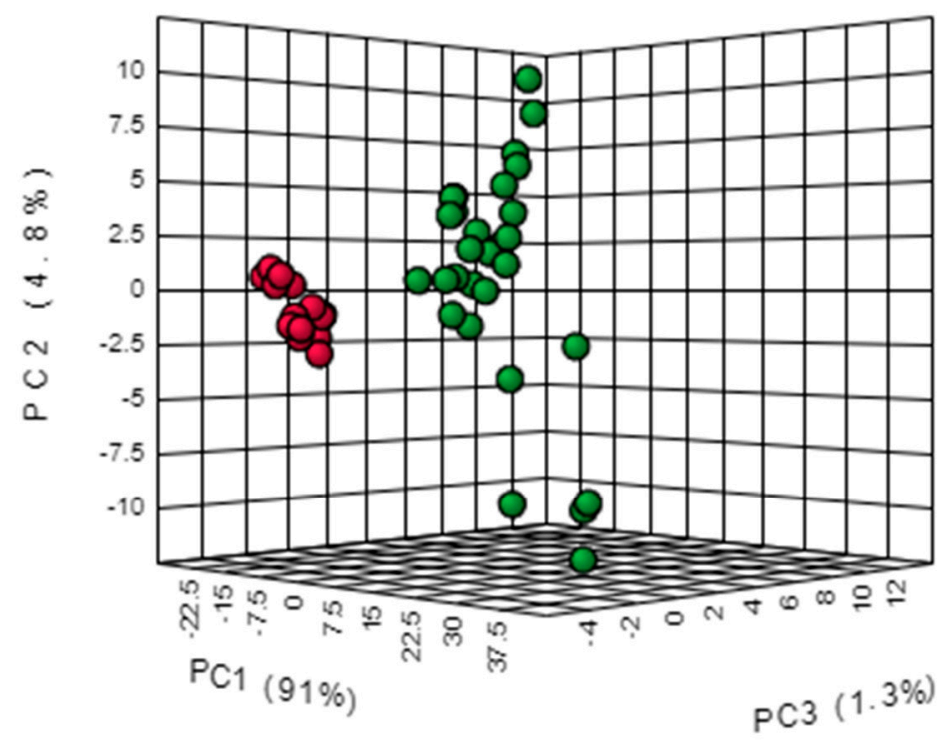

Figure 4. 3D Score plot of principal components analysis (PCA).

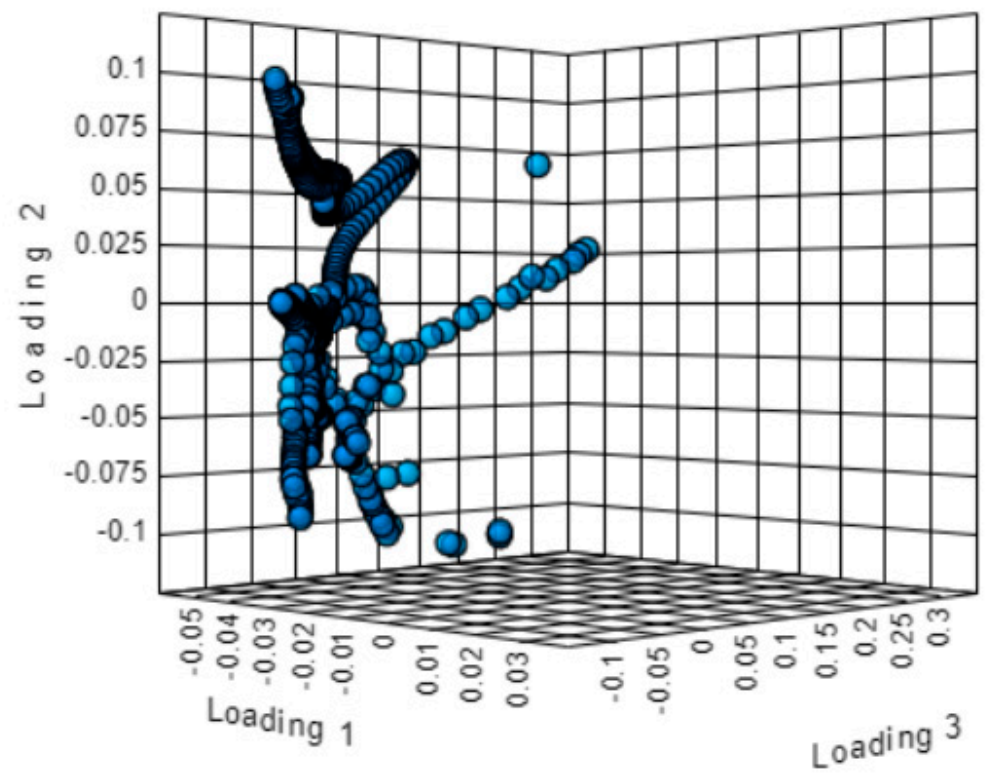

Figure 5. 3D loading plot of principal components analysis (PCA). 


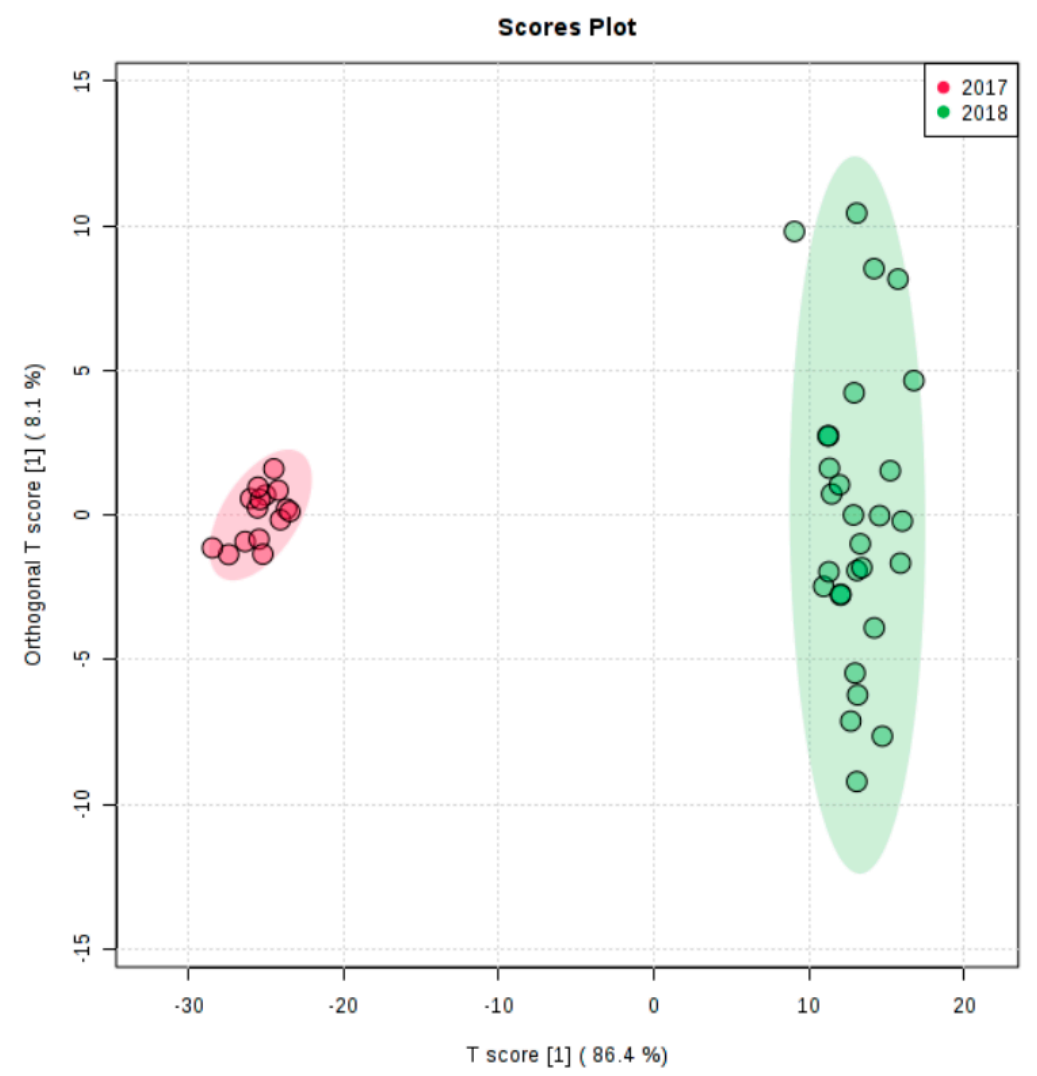

Figure 6. Orthogonal Partial Least Squares-Discrimination (orthoPLS-DA) using MetaboAnalyst.

\subsubsection{Statistical Models Comparison}

The evaluation of the total antioxidant capacity of pistachio oil samples through an ABTS assay showed that TAC and their scavenging capacity could be statistically differentiated, among the years of harvesting, as was also observed with the results based on R-value. It is worth noticing that in the case of AV, FFA, and HPLC-fluorescence analysis, there were no statistically significant differences between 2017 and 2018, at a 95\% confidence level. However, FTIR spectroscopy combined with the statistical methods represent an appropriate rapid technique to discriminate pistachio oils of different quality, based on their antioxidant profile.

\section{Materials and Methods}

\subsection{Samples}

A total of 45 pistachio samples of the Greek variety 'Aegina' were provided by pistachio farmers from eight different regions of Greece (Aegina, Megara, Phthiotis, Evia, Volos, Trizina, Thiva, and Avlona) during the 2017 and 2018 harvest seasons. Due to alternate bearing, the number of samples of 2017 was less than the succeeding year. The pistachios were sound and had the typical characteristics of the variety. They were dried under the sun or mechanically at moisture level $5 \%-7 \%$, after dehulling at farm level. In the laboratory, each sample was shelled and finely ground in an IKA M 20 (IKA, Königswinter, Germany) laboratory mill, at a maximum rotational speed 20,000 rpm, followed by particle size separation using sieves $(500 \mu \mathrm{m}<$ size $<800 \mu \mathrm{m})$. After preparation, all samples were put in sealed bags, protected from light, and stored in the freezer $\left(-20^{\circ} \mathrm{C}\right)$ until analysis.

\subsection{Reagents}

Petroleum ether, 2,2-diphenyl-1-(2,4,6-trinitrophenyl)hydrazine (DPPH), 2,2'-azinobis(3ethylbenzothiazoline-6-sulfonic acid diammonium salt (ABTS), potassium persulfate $\left(\mathrm{K}_{2} \mathrm{~S}_{2} \mathrm{O}_{8}\right)$, 
potassium hydrogen phthalate (KHP), sodium hydroxide pellets $(\mathrm{NaOH})$, 6-hydroxy-2,5,7,8tetramethylchroman-2-carboxylic acid (Trolox), ethyl acetate, tetrahydrofuran (THF), n-heptane, cyclohexane $99.8 \%$, methanol $(\mathrm{MeOH})$, and ethanol $(\mathrm{EtOH})$ were purchased from Sigma-Aldrich (Steinhein, Germany). (+)- $\alpha-,(+)-\beta-,(+)-\gamma-$, and $(+)-\delta$-tocopherol standards of $99.99 \%$ purity were obtained from Merck (Darmstadt, Germany). Distilled water and phenolphthalein indicator solution were also used. All compounds and solvents were of analytical grade.

\subsection{Oil Extraction}

Pistachio oil was extracted from $4 \mathrm{~g}$ of kernel flour with $250 \mathrm{~mL}$ of petroleum ether in a Soxhlet apparatus for $6 \mathrm{~h}$, according to the AOAC Official Method 948.22. After evaporation of the solvent under reduced pressure, the oil was weighed to measure the lipids' mass and was kept in a freezer $\left(-20^{\circ} \mathrm{C}\right)$ to maintain its initial quality, until analysis. The extraction was carried out in triplicates and the mean value with the standard deviation was calculated.

\subsection{Evaluation of the Antioxidant Capacity}

\subsubsection{DPPH Assay}

DPPH radical-scavenging capacity was determined according to Minioti and Georgiou (2010) [17], with some modifications using a JASCO V-550 spectrophotometer (JASCO Corporation, Tokyo, Japan). Briefly, $100 \mu \mathrm{L}$ of pistachio oil were mixed with $4 \mathrm{~mL}$ of DPPH working solution $\left(8.1 \times 10^{-5} \mathrm{M}\right.$ working solution of the DPPH radical in ethyl acetate). The reaction mixture was vigorously stirred for a few seconds and kept in a dark place for $30 \mathrm{~min}$, at room temperature. Absorbencies were measured at $515 \mathrm{~nm}$ against a blank ( $100 \mu \mathrm{L}$ of ethyl acetate instead of pistachio oil). Pistachio oil antioxidants scavenged the DPPH radical, resulting in decolorization of its purple solution. Analyses were performed in triplicates. The scavenging capacity was calculated using Equation (7):

$$
\text { Scavenging capacity }=\left[\left(\mathrm{A}_{515} \text { of control }-\mathrm{A}_{515} \text { of sample }\right) / \mathrm{A}_{515} \text { of control }\right] \times 100
$$

A calibration curve $(0.08-1 \mathrm{mM})$ was constructed using Trolox as the external standard and the obtained values were expressed as $\mathrm{mmol} / \mathrm{L}$ of Trolox equivalents per $\mathrm{mL}$ of oil.

\subsubsection{ABTS Assay}

The ABTS assay was slightly modified, based on the methods of Rajaei et al. (2010) [35] and Torres-Martinez et al. (2017) [36], using an Agilent 8453 spectrophotometer. In brief, $96 \mathrm{mg}$ of ABTS with distilled water were diluted in a $25 \mathrm{~mL}$ volumetric flask and $440 \mu \mathrm{L}$ of $\mathrm{K}_{2} \mathrm{O}_{8} \mathrm{~S}_{2}$ solution $(0.14 \mathrm{M}$ in distilled water) were added. The mixture was maintained for $18 \mathrm{~h}$, protected by light, at room temperature for stabilization of the ABTS oxidation. Prior to further use, the $\mathrm{ABTS}^{+}$solution was diluted with $\mathrm{EtOH}$, at an absorbance value of $0.7 \pm 0.005$ (working solution). Antioxidant capacity was evaluated by measuring the scavenging effect of $100 \mu \mathrm{L}$ of pistachio oil, mixed with $2 \mathrm{~mL}$ of ABTS working solution, followed by shaking and incubation in the dark, for $6 \mathrm{~min}$ at room temperature. The decrease in absorbance was then measured at $734 \mathrm{~nm}$ against a control solution (100 $\mu \mathrm{L}$ of EtOH). All measurements were performed in triplicates. The scavenging capacity was calculated using Equation (8):

$$
\text { Scavenging capacity }=\left[\left(\mathrm{A}_{734} \text { of control }-\mathrm{A}_{734} \text { of sample }\right) / \mathrm{A}_{734} \text { of control }\right] \times 100
$$

Trolox was used as a reference compound for the calibration curve with a concentration range of $0.05-1 \mathrm{mM}$ and a total antioxidant capacity, expressed as $\mathrm{mmol} / \mathrm{L}$ of Trolox equivalents per $\mathrm{mL}$ of oil, was calculated and reported as mean $\pm \mathrm{SD}$. 


\subsection{Quality Assessment of Pistachio Oil}

\subsubsection{UV-Vis Assessment}

The Agilent Cary 60 UV-Vis spectrophotometer (Agilent Technologies, Mississauga, ON, Canada) and rectangular quartz cuvettes with an optical length of $1 \mathrm{~cm}$ were used according to EEC No 2568/91 (Annex IX of the Regulation). Pistachio oil samples (45 in total) were diluted in cyclohexane. A total of $0.1 \mathrm{~g}$ of pistachio oil was weighed accurately into a $10 \mathrm{~mL}$ graduated flask, filled up to the mark with the solvent, and homogenized. The resulting solution $(10 \mathrm{~g} / \mathrm{L})$ was perfectly clear. If opalescence or turbidity was present, it was filtered through the paper. All samples were measured in cuvettes, running a solvent blank as a reference. Absorption measurements for purity determination were made at $232,268,270$, and $274 \mathrm{~nm}$ in triplicates, and the average was used for the determination of pistachio oil purity. K values were calculated according to Equation (9):

$$
\mathrm{k}=\mathrm{A} /(\mathrm{C} \times \mathrm{s})
$$

where $\mathrm{A}$ is the absorbance at the specified nanometer; $\mathrm{C}$ is the concentration in grams per liter; and $\mathrm{s}$ is the cuvette thickness in centimeter. Delta $(\Delta) \mathrm{k}$ and R-value were evaluated using Equations (10) and (11):

$$
\begin{aligned}
& \text { Delta }(\Delta) \mathrm{k}=\mathrm{k}_{270}-\left[\left(\mathrm{k}_{268}+\mathrm{k}_{274}\right) / 2\right] \\
& \text { R-value was calculated }=\mathrm{k}_{232} / \mathrm{k}_{270}
\end{aligned}
$$

\subsubsection{Determination of AV and FFA}

The AV and FFA content were determined in triplicates, according to Otemuyiwa and Adewusi (2013) [22]. In brief, titration of pistachio oil (1 g) dissolved in $5 \mathrm{~mL}$ EtOH was applied, using a $0.1 \mathrm{M} \mathrm{NaOH}$ solution as the standard reagent to a phenolphthalein endpoint (when the addition of a single drop of alkali produces a slight but definite color change that persists for at least $15 \mathrm{~s}$ ). The AV value was expressed as oleic acid, according to Equation (12). All determinations were performed in triplicates. The acid value was calculated according to Equation (13):

$$
\mathrm{AV}=(56 \times \mathrm{C} \times \mathrm{V}) / \mathrm{m}
$$

where $\mathrm{V}$ is the titration volume $(\mathrm{mL})$ of the standard volumetric $\mathrm{NaOH}$ solution used; $\mathrm{C}$ is the concentration $(\mathrm{M})$ of the standard volumetric $\mathrm{NaOH}$ solution used; and $\mathrm{m}$ is the mass ( $\mathrm{g}$ ) of the pistachio oil sample. The percentage of FFAs in the pistachio oil was calculated using Equation (13):

$$
\% \text { FFA }=0.503 \times \mathrm{AV}
$$

Then, the AV and FFA mean values and the corresponding SDs were calculated.

\subsection{Tocopherol Analysis}

\subsubsection{Apparatus and Chromatographic Conditions}

The chromatographic analysis was carried out in an analytical HPLC unit equipped with a JASCO PU 980 pump, with a $100 \mu \mathrm{L}$ injection loop, a JASCO FP920 fluorescence detector (Co. Ltd., Tokyo, Japan) supported by Clarity Lite software (DataApex, Prague, Czech Republic) for data processing, and an ODS Hypersyl column $(4.6 \times 250 \mathrm{~mm}, 5 \mu \mathrm{m}$ particle size, Thermo Fisher Scientific Inc., Waltham, MA, USA).

The determination of the $\alpha_{-}^{-}, \beta-, \gamma_{-}$, and $\delta$-tocopherol (T) content using HPLC, followed the ISO 9936:2006 standard. The mobile phase consisted of the THF/n-heptane $(4: 96 v / v)$ at a flow rate of $1.0 \mathrm{~mL} / \mathrm{min}$ and the injection volume was $10 \mu \mathrm{L}$. The effluent was detected in a fluorescence detector, with an excitation filter at $295 \mathrm{~nm}$ and an emission wavelength at $330 \mathrm{~nm}$. The system was operated at 
ambient temperatures. The tocopherol compounds were identified by chromatographic comparisons of the retention times of the analytes in a standard solution and quantified by the respective calibration curves. The results were obtained from triple measurements, and the mean values and corresponding SDs were calculated.

\subsubsection{Standard Solutions}

Stock standard solutions, $\alpha-\mathrm{T}(96.53 \mu \mathrm{g} / \mathrm{mL}), \beta-\mathrm{T}(85.74 \mu \mathrm{g} / \mathrm{mL}), \gamma-\mathrm{T}(87.40 \mu \mathrm{g} / \mathrm{mL})$, and $\delta$-T $(81.14$ $\mu \mathrm{g} / \mathrm{mL}$ ) in $\mathrm{n}$-heptane were prepared and stored in the dark at $-20{ }^{\circ} \mathrm{C}$. Combined working standard mixtures, with concentrations in the expected sample ranges, were prepared daily from the stock standard solutions, by diluting appropriate volumes of stock solutions with n-heptane. Then, a calibration curve for each tocopherol was constructed.

\subsubsection{Validation Method}

Calibration and linearity: Calibration curves were prepared using standard solution of vitamin $\mathrm{E}$ isomers at nine concentrations $(\mathrm{C})$, ranging from $0.15-20 \mu \mathrm{g} / \mathrm{mL}$.

Recovery: Extraction recoveries were evaluated by adding known amounts of isomers $(+)-\alpha-\mathrm{T}$, $(+)-\beta-T,(+)-\gamma-T$, and $(+)-\delta-T$ to the pistachio oil samples. The amounts added were of low, medium and high tocopherol content $(0.2,10$ and $20 \mu \mathrm{g} / \mathrm{mL})$. Recovery was calculated by Equation (14):

$$
\text { Recovery }=(C \text { of spiked sample } /(C \text { of sample }+C \text { of standard added })) \times 100
$$

Analytical precision: Interday precision was determined by analyzing two concentrations (15 and $20 \mu \mathrm{g} / \mathrm{mL}$ ) of standard vitamin E isomers in three replicates on three different days. The following equation was used:

$$
\text { Precision, } \%=(S D / \text { Mean C }) \times 100
$$

The repeatability of the tocopherols' measurements in pistachio oil was calculated by Equation (15).

\subsection{FTIR Spectra Recording}

The FTIR spectra of the pistachio oil samples were recorded in triplicates on a Thermo Nicolet 6700 FTIR spectrophotometer (Thermo Electron Corporation, Madison, WI, USA) equipped with a deuterated triglycine sulfate (DTGS) detector. The spectra were in an attenuated total reflection (ATR) mode with a Horizontal ATR accessory from Spectra-Tech Inc. (Stamford, CT, USA). The accessory was equipped with a ZnSe-ATR crystal of a trapezoid shape $(800 \times 10 \times 4 \mathrm{~mm})$. The crystal provided an angle of incidence of $45^{\circ}$ and was enclosed in a stainless-steel cuvette. For spectra recording, an aliquot of $200 \mu \mathrm{L}$ of pistachio oil or tocopherol standard mixture was poured on the ATR crystal and allowed to dry, forming a uniform film. Spectra were recorded with a resolution of $4 \mathrm{~cm}^{-1}$ and 100 scans. The speed of the interferometer moving mirror was $0.6329 \mathrm{~mm} / \mathrm{s}$. Background spectrum was collected using only ATR crystal, prior to spectrum recording of each sample.

FTIR spectra were smoothed using the Savitsky-Golay algorithm (5-point moving second-degree polynomial) and the baseline was corrected using the 'automatic baseline correct function' (second-degree polynomial, twenty iterations). Then, the average spectrum of each sample was measured and normalized (absorbance maximum value of 1). Each average spectrum was extracted and saved as a csv file for their use in discriminant analysis. Spectral data collection and processing was carried out using the OMNIC ver. 8.2.0.387 software (Thermo Fisher Scientific Inc., Waltham, MA, USA). 


\subsection{Statistical Analysis}

Discriminant analysis was performed using IBM SPSS Statistics 22 (ver. 8.0.0.245) (SPSS Inc., Chicago, IL, USA) and the MetaboAnalyst 4.0 software (McGill University, Montreal, QC, Canada) for a comprehensive and integrative data analysis.

\section{Conclusions}

The results of this work showed that the pistachio oil samples of the variety "Aegina" were within the limits set by the specific standards in terms of high quality. The oil yields of the samples from the two harvest seasons $(2017,2018)$ were found to be similar, while statistically significant differences were evident for the antioxidant capacity and the R-value between pistachio oil samples, from different years of harvesting. These differences might be attributed to agroclimatic factors, such as different agricultural practices, average temperature, and rainfall from year to year. The FTIR spectroscopy succeeded to classify pistachio oil samples according to the differences which are related to quality parameters, particularly described by the antioxidant capacity, and the R-value. The developed method is fast, accurate, non-destructive, with no excessive sample preparation, and has the additional advantage of not requiring the use of large quantities of solvents, being especially suitable for the screening of large number of samples. Furthermore, the present results provide evidence that the FTIR method could be a promising discriminating tool against fraud related to plant-derived oils, through the use of quality parameters as indicators.

Author Contributions: Conceptualization, C.S.P., L.V., and M.G.; methodology, C.S.P and M.G.; formal analysis, L.V., D.A., and A.M.; investigation, L.V., D.A., and A.M.; data curation, L.V., D.A., and A.M.; writing-original draft preparation, L.V. and M.G.; writing-review and editing, L.V., M.G., and C.S.P. All authors have read and agreed to the published version of the manuscript.

Funding: This research received no external funding.

Acknowledgments: This research work was supported by the Hellenic Foundation for Research and Innovation (HFRI) and the General Secretariat for Research and Technology (GSRT), under the HFRI PhD Fellowship grant (GA. no. 1313).
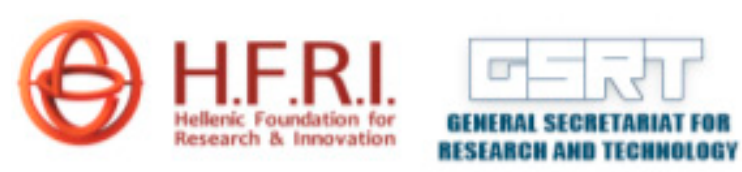

Conflicts of Interest: The authors declare no conflict of interest.

\section{References}

1. Gentile, C.; Tesoriere, L.; Butera, D.; Fazzari, M.; Monastero, M.; Allegra, M.; Livrea, M.A. Antioxidant Activity of Sicilian Pistachio (Pistacia vera L. Var. Bronte) Nut Extract and Its Bioactive Components. J. Agric. Food Chem. 2007, 55, 643-648. [CrossRef] [PubMed]

2. Rodríguez-Bencomo, J.J.; Kelebek, S.; Ahmet, S.S.; Rodríguez-Alcalá, L.M.; Fontecha, J.; Selli, S. Characterization of the Aroma-Active, Phenolic, and Lipid Profiles of the Pistachio (Pistacia vera L.) Nut as Affected by the Single and Double Roasting Process. J. Agric. Food Chem. 2015, 63, 7830-7839.

3. Halvorsen, B.L.; Carlsen, M.H.; Phillips, K.M.; Bøhn, S.K.; Holte, K.; Jacobs, D.R., Jr.; Blomhoff, R. Content of redox-active compounds (ie, antioxidants) in foods consumed in the United States. Am. J. Clin. Nutr. 2006, 84, 95-135. [CrossRef] [PubMed]

4. John, J.A.; Shahidi, F. Phenolic compounds and antioxidant activity of Brazil nut (Bertholletia excelsa). J Funct. Foods 2010, 2, 196-209. [CrossRef]

5. Desamparados, S.; Ojeda-Amador, R.; Fregapane, G. Virgin Pistachio (Pistachia vera L.) Oil. In Fruit Oils: Chemistry and Functionality; Ramadan, M., Ed.; Springer: Cham, Switzerland, 2019; p. 183. 
6. Tsantili, E.; Takidelli, C.; Christopoulos, M.V.; Lambrinea, E.; Rouskas, D.; Roussos, P.A. Physical, compositional and sensory differences in nuts among pistachio (Pistachia vera L.) varieties. Sci. Hortic. 2010, 125, 562-568. [CrossRef]

7. Ojeda-Amador, R.M.; Fregapane, G.; Desamparados, S.M. Composition and properties of virgin pistachio oils and their by-products from different cultivars. Food Chem. 2018, 240, 123-130. [CrossRef]

8. Aceña, L.; Vera, L.; Guasch, J.; Busto, O.; Mestres, M. Comparative study of two extraction techniques to obtain representative aroma extracts for being analysed by gas chromatography-olfactometry: Application to roasted pistachio aroma. J. Chromatogr. A 2010, 1217, 7781-7787. [CrossRef]

9. Kay, C.D.; Gebauer, S.K.; West, S.G.; Kris-Etherton, P.M. Pistachios Increase Serum Antioxidants and Lower Serum Oxidized-LDL in Hypercholesterolemic Adults. J. Nutr. 2010, 140, 1093-1098. [CrossRef]

10. Martorana, M.; Arcoraci, T.; Rizza, L.; Cristani, M.; Bonina, F.P.; Saija, A.; Trombetta, D.; Tomaino, A. In vitro antioxidant and in vivo photoprotective effect of pistachio (Pistacia vera L., variety Bronte) seed and skin extracts. Fitoterapia 2013, 85, 41-48. [CrossRef]

11. Houshia, O.J.; Zaid, O.; Shqair, H.; Zaid, M.; Fashafsheh, N.; Bzoor, R. Effect of Olive Oil Adulteration on Peroxide Value, Delta-K and on the Acidity Nabali-Baladi Olive Oil Quality. Adv. Life Sci. 2014, 4, 235-244.

12. El-Abassy, R.M.; Donfack, P.; Materny, A. Rapid Determination of Free Fatty Acid in Extra Virgin Olive Oil by Raman Spectroscopy and Multivariate Analysis. J. Am. Oil Chem. Soc. 2009, 86, 507-511. [CrossRef]

13. Servili, M.; Montedoro, G. Contribution of phenolic compounds to virgin olive oil. Eur. J. Lipid Sci. Technol. 2002, 104, 602-613. [CrossRef]

14. Juhaimi, F.A.; Ozcan, M.M.; Ghafoor, K.; Babiker, E.E.; Hussain, S. Comparison of cold-pressing and soxhlet extraction systems for bioactive compounds, antioxidant properties, polyphenols, fatty acids and tocopherols in eight nut oils. J. Food Sci. Technol. 2018, 55, 3163-3173. [CrossRef] [PubMed]

15. Geana, E.I.; Ciucure, C.T.; Apetrei, C.; Artem, V. Application of Spectroscopic UV-Vis and FT-IR Screening Techniques Coupled with Multivariate Statistical Analysis for Red Wine Authentication: Varietal and Vintage Year Discrimination. Molecules 2019, 24, 4166. [CrossRef] [PubMed]

16. Pérez-Ràfols, C.; Subirats, X.; Serrano, N.; Díaz-Cruz, J.M. New discrimination tools for harvest year and varieties of white wines based on hydrophilic interaction liquid chromatography with amperometric detection. Talanta 2019, 201, 104-110. [CrossRef]

17. Minioti, K.S.; Georgiou, C.A. Comparison of different tests used in mapping the Greek virgin olive oil production for the determination of its total antioxidant capacity. Grasas Y Aceites 2010, 61, 45-51.

18. Yu, J.; Wang, H.; Zhan, J.; Huang, W. Review of recent UV-Vis and infrared spectroscopy researches on wine detection and discrimination. Appl. Spectrosc. 2017, 53, 65-86. [CrossRef]

19. Rowshan, V.; Bahmanzadegan, A.; Saharkhiz, M.J. Influence of storage conditions on the essential oil composition of Thymus daenensis Celak. Ind. Crop. Prod. 2013, 49, 97-101. [CrossRef]

20. Kim, D.O.; Lee, K.W.; Lee, H.J.; Lee, C.Y. Vitamin C equivalent antioxidant capacity (VCEAC) of phenolic phytochemicals. J. Agric. Food Chem. 2002, 50, 3713-3717. [CrossRef]

21. Floegel, A.; Kim, D.O.; Chung, S.J.; Koo, S.I.; Chun, O.K. Comparison of ABTS/DPPH assays to measure antioxidant capacity in popular antioxidant-rich US foods. J. Food Compos. Anal. 2011, 24, 1043-1048. [CrossRef]

22. Otemuyiwa, I.O.; Adewusi, S.R.A. Fatty Acid, Carotenoid and Tocopherol Content of Some Fast Foods from a Nigerian Eatery. Food Nutr. Res. 2013, 1, 82-86.

23. Martínez, M.L.; Fabani, M.P.; Baroni, M.V.; Huaman, R.N.M.; Ighani, M.; Maestri, D.M.; Wunderlin, D.; Tapia, A.; Feresin, G.E. Argentinian pistachio oil and flour: A potential novel approach of pistachio nut utilization. J. Food Sci. Technol. 2016, 53, 2260-2269. [CrossRef] [PubMed]

24. Uncu, O.; Ozen, B.; Tokatli, F. Use of FTIR and UV-visible spectroscopy in determination of chemical characteristics of olive oils. Talanta 2019, 201, 65-73. [CrossRef] [PubMed]

25. Luna, A.S.; Silva, A.P.; Ferré, J.; Boqué, R. Classification of edible oils and modeling of their physico-chemical properties by chemometric methods using mid-IR spectroscopy. Spectrochim. Acta A 2013, 100, 109-114. [CrossRef]

26. Gericke, A.; Hühnerfuss, H. Investigation of Z- and E-Unsaturated Fatty Acids, Fatty Acid Esters, and Fatty Alcohols at the Air/Water Interface by Infrared Spectroscopy. Langmuir 1995, 11, 225-230. [CrossRef] 
27. Dymińska, L.; Calik, M.; Albegar, A.M.M.; Zając, A.; Kostyń, K.; Lorenc, J.; Hanuza, J. Quantitative determination of the iodine values of unsaturated plant oils using infrared and Raman spectroscopy methods. Int. J. Food Prop. 2017, 20, 2003-2015. [CrossRef]

28. Rohman, A.; CheMan, Y.B. Fourier transform infrared (FTIR) spectroscopy for analysis of extra virgin olive oil adulterated with palm oil. Food Res. Int. 2010, 43, 886-892. [CrossRef]

29. Moros, J.; Roth, M.; Garrigues, S.; Guardia, M. Preliminary studies about thermal degradation of edible oils through attenuated total reflectance mid-infrared spectrometry. Food Chem. 2009, 114, 1529-1536. [CrossRef]

30. Christy, A.A.; Egeberg, P.K. Quantitative determination of saturated and unsaturated fatty acids in edible oils by infrared spectroscopy and chemometrics. Chemom. Intell. Lab. Syst. 2006, 82, 130-136. [CrossRef]

31. Gutiérrez, L.F.; Quiñones-Segura, Y.; Sanchez-Reinoso, Z.; Leonardo, D.D.; Abril, J.I. Physicochemical properties of oils extracted from $\gamma$-irradiated Sacha Inchi (Plukenetiavolubilis L.) seeds. Food Chem. 2017, 237, 581-587.

32. Bullo, M.; Juanola-Falgarona, M.; Hernandez-Alonso, P.; Salas-Salvado, J. Nutrition attributes and health effects of pistachio nuts. Br. J. Nutr. 2015, 113, 879-893. [CrossRef] [PubMed]

33. Ahmed, M.K.; Daun, J.K.; Przybylski, R. FT-IR based methodology for quantitation of total tocopherols, tocotrienols and plastochromanol-8 in vegetable oils. J. Food Compos. Anal. 2005, 18, 359-364. [CrossRef]

34. Rosenkrantz, H. Infra-red absorption spectra of tocopherols and related structure. J. Biol. Chem. 1948, 173, 439-447. [PubMed]

35. Rajaei, A.; Barzegar, M.; Mobarez, A.M.; Sahari, M.A.; Esfahani, Z.H. Antioxidant, anti-microbial and antimutagenicity activities of pistachio (Pistachia vera) green hull extract. Food Chem. Toxicol. 2010, 48, 107-112. [CrossRef]

36. Torres-Martínez, R.; García-Rodríguez, Y.M.; Ríos-Chávez, P.; Saavedra-Molina, A.; López-Meza, J.E.; Ochoa-Zarzosa, A.; Garciglia, R.S. Antioxidant Activity of the Essential Oil and its Major Terpenes of Satureja macrostema (Moc. and Sessé ex Benth.) Briq. Pharm. Mag. 2018, 13, 875-880.

Sample Availability: Samples of the compounds are available from the authors.

(C) 2020 by the authors. Licensee MDPI, Basel, Switzerland. This article is an open access article distributed under the terms and conditions of the Creative Commons Attribution (CC BY) license (http://creativecommons.org/licenses/by/4.0/). 